The c/a Ratio in Quenched Fe-C and Fe-N steels - a Heuristic Story

O. Sherby, J. Wadsworth, D. Lesuer, C. Syn

February 2, 2006

THERMEC 2006

Vancouver, Canada

July 4, 2006 through July 8, 2006 
This document was prepared as an account of work sponsored by an agency of the United States Government. Neither the United States Government nor the University of California nor any of their employees, makes any warranty, express or implied, or assumes any legal liability or responsibility for the accuracy, completeness, or usefulness of any information, apparatus, product, or process disclosed, or represents that its use would not infringe privately owned rights. Reference herein to any specific commercial product, process, or service by trade name, trademark, manufacturer, or otherwise, does not necessarily constitute or imply its endorsement, recommendation, or favoring by the United States Government or the University of California. The views and opinions of authors expressed herein do not necessarily state or reflect those of the United States Government or the University of California, and shall not be used for advertising or product endorsement purposes. 


\title{
The c/a Ratio in Quenched Fe-C and Fe-N steels - a Heuristic Story
}

\author{
O. D. Sherby ${ }^{1, a}$, J. Wadsworth", b, D. R. Lesuer ${ }^{3, \mathrm{c}}$ and C. K. Syn ${ }^{3, d}$ \\ ${ }^{1}$ Stanford University, Stanford, CA 94305-2205, USA \\ ${ }^{2}$ Oak Ridge National Laboratory, Oak Ridge, TN 37831-6255, USA \\ ${ }^{3}$ Lawrence Livermore National Laboratory, Livermore, CA 94551, USA

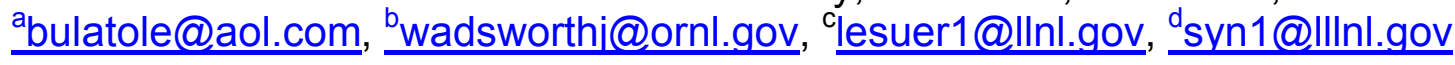

Keywords: c/a ratio, quenched martensite, Fe-C steels, Fe-N steels, interstitial carbon, particles, phase transformation, crystal structure, valence

\begin{abstract}
The body-centered tetragonal (BCT) structure in quenched Fe-C steels is usually illustrated to show a linear change in the $\mathrm{c}$ and a axes with an increase in carbon content from 0 to $1.4 \% \mathrm{C}$. The work of Campbell and Fink, however, shows that this continuous linear relationship is not correct. Rather, it was shown that the body-centered-cubic (BCC) structure is the stable structure from 0 to $0.6 \mathrm{wt} \% \mathrm{C}$ with the $\mathrm{c} / \mathrm{a}$ ratio equal to unity. An abrupt change in the c/a ratio to 1.02 occurs at $0.6 \mathrm{wt} \% \mathrm{C}$. The $\mathrm{BCT}$ structure forms, and the c/a ratio increases with further increase in carbon content. An identical observation is noted in quenched Fe-N steels. This discontinuity is explained by a change in the transformation process. It is proposed that a two-step transformation process occurs in the low carbon region, with the FCC first transforming to HCP and then from HCP to BCC. In the high carbon region, the FCC structure transforms to the BCT structure. The results are explained with the Engel-Brewer theory of valence and crystal structure of the elements. An understanding of the strength of quenched iron-carbon steels plays a key role in the proposed explanation of the c/a anomaly based on interstitial solutes and precipitates.
\end{abstract}

\section{Introduction}

The crystal structure of iron and iron-carbon alloys is unusual. Among the 64 elements that exhibit polymorphism, only iron exhibits all three of the crystal structures commonly observed in metals. These are the body-centered-cubic (BCC) structure, the hexagonal-close-packed (HCP) structure, and the face-centered-cubic (FCC) structure. Furthermore, iron is the only element where the BCC structure exists at low temperature and then transforms to either of the two close-packed structures at high temperature. Figures 1 and 2 illustrate these observations. The iron-carbon phase diagram up to the maximum solubility of carbon in iron is shown in Fig. 1. The data represent the phases observed at atmospheric pressure. Only transformations involving BCC and FCC phases are observed. Figure 2 shows the phases present in pure iron as a function of pressure and temperature. In this case, all three crystal structures are depicted with the triple point observed at about 11.3 $\mathrm{GPa}$ and $760 \mathrm{~K}$. These crystal structure relations are pertinent to the present investigation for interpretation of crystal structure changes in quenched Fe-C steels.

A non-equilibrium phase is observed in quenched $\mathrm{Fe}-\mathrm{C}$ steels. It is a meta-stable phase known as body-centered-tetragonal (BCT) iron. The tetragonality is described by plotting the values of the long axis of the elongated cube (c axis) and the short axis of the elongated cube (a axis) as a function of the carbon content. An example is shown in Fig. 3 where the lattice parameters for the 
$\mathrm{c}$ and a directions are plotted as a function of carbon content [1]. Data points from measured values are shown from about $0.6 \mathrm{wt}$ to $1.4 \mathrm{wt} \% \mathrm{C}$ where tetragonal BCT iron was observed. Extrapolation of the lines containing the data points to zero carbon gave the result that the values of $\mathrm{c}$ and a are identical. And, this value is equal to the known value of the lattice parameter of pure iron. No discontinuity in the phase transformation process is expected as a function of carbon content. The result is that the formation of a single meta-stable phase, namely martensite, will form with the $\mathrm{c}$ values and a values changing monotonically with increase in carbon content.

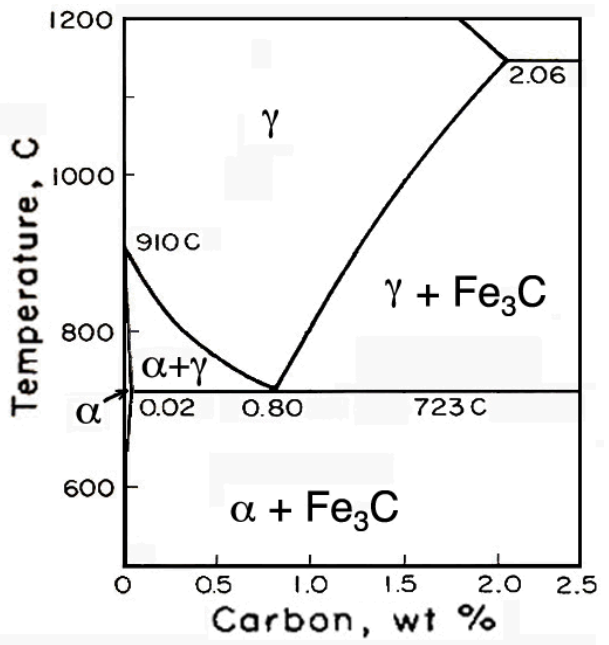

Fig. 1. Partial phase diagram of FeC system from zero to $2.5 \mathrm{wt} \% \mathrm{C}$

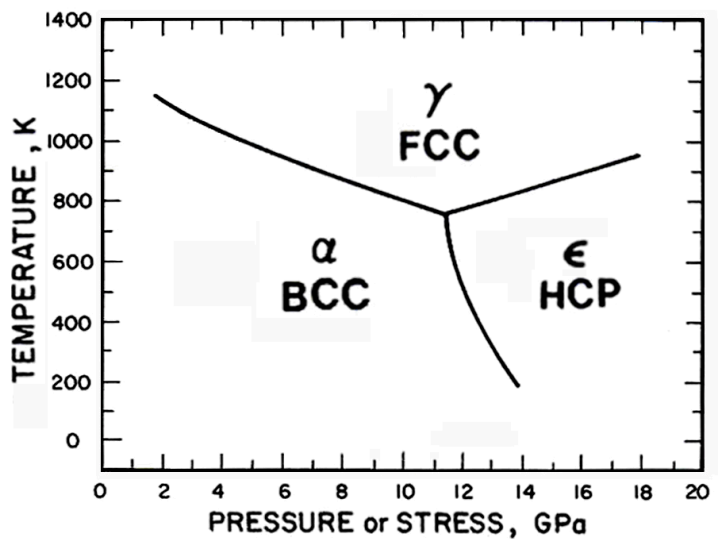

Fig.2. Temperature-Pressure diagram of pure iron

\section{The Problem}

The depicted change, shown in Fig. 3 , of the $\mathrm{c}$ and a dimensions with carbon content below $0.6 \mathrm{wt} \%$ is not realistic. This is because the values of $\mathrm{c}$ and a are identical at low carbon contents (less than $0.59 \mathrm{wt} \% \mathrm{C}$ ) and equal to the lattice parameter of pure iron. This result was pointed out by Fink and Campbell [2] in 1926. These authors were the first to discover the body-centered tetragonal structure in quenched high carbon $\mathrm{Fe}-\mathrm{C}$ alloys $(0.9,1.13$ and 1.5 $\mathrm{wt} \% \mathrm{C})$. The quenched $\mathrm{Fe}-\mathrm{C}$ alloys with $0.05,0.10,0.21 \quad w t \% \quad C$, however, yielded identical values of $\mathrm{c}$ and $\mathrm{a}$, that is $\mathrm{c} / \mathrm{a}=1$. Honda and Nishiyama [3] showed similar results with BCT structures observed only in the carbon range from 0.59 to 1.75

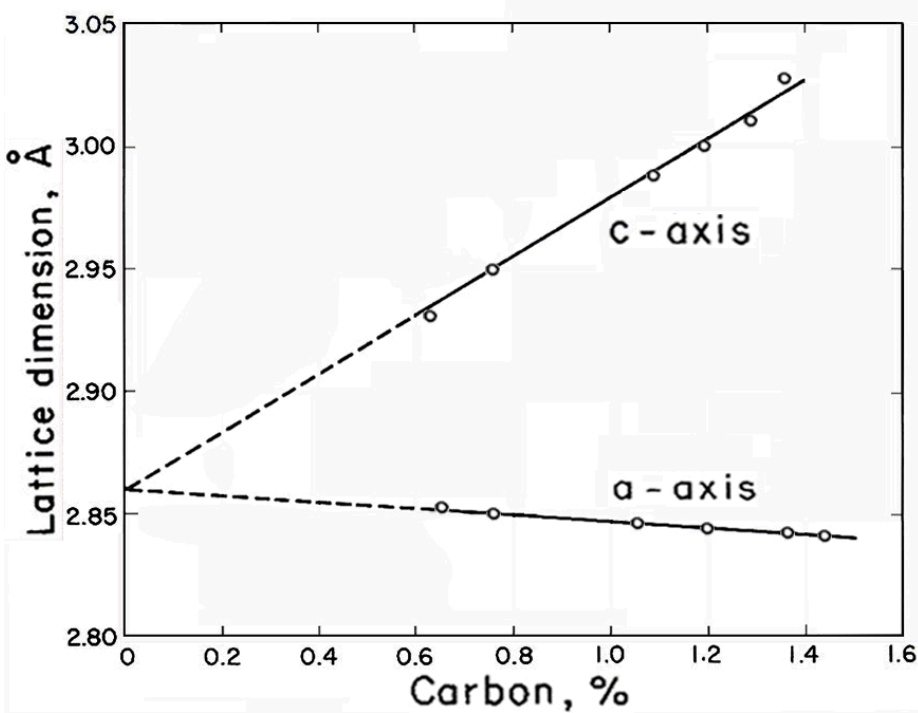

Fig. 3. Lattice parameters versus carbon content of quenched martensite in Fe-C steels. Data reported from Bain and Paxton [1] 
$\mathrm{wt} \%$ C. It is clear that the plot given in Fig. 3 is misleading and an alternate approach is needed. It was decided to replot the data in Fig. 3 as the ratio of c/a rather than separate values of $\mathrm{c}$ and a.

Figure 4 is a plot of the c/a ratio as a function of carbon content. The result shows two distinct regions in the formation of martensite, given as I and II in the figure. Range I is from zero to about $0.6 \mathrm{wt} \% \mathrm{C}$ showing the $\mathrm{c} / \mathrm{a}$ ratio equal to unity, and Range II is from 0.6 to $1.75 \mathrm{wt} \% \mathrm{C}$ where the BCT structure was observed. The extrapolation of the line in Range II, given as a dotted line, leads to a c/a ratio of 1 at zero carbon content. It would appear that a different transformation process occurs in Range I that inhibits the transformation process in Range II to continue into Range I. The pattern shown in Fig. 4 for Fe-C steels is also observed in Fe-N steels [5]. Figure 5 shows the same plot for quenched Fe-N steels except that the nitrogen content was reported as atom percent. The same two ranges are observed with the sharp break at 2.85 atom percent nitrogen. Remarkably, this atom percent of nitrogen is identical to the atom percent of carbon at the break point shown in Fig. 3 when converted from $0.6 \mathrm{wt} \%$ carbon.

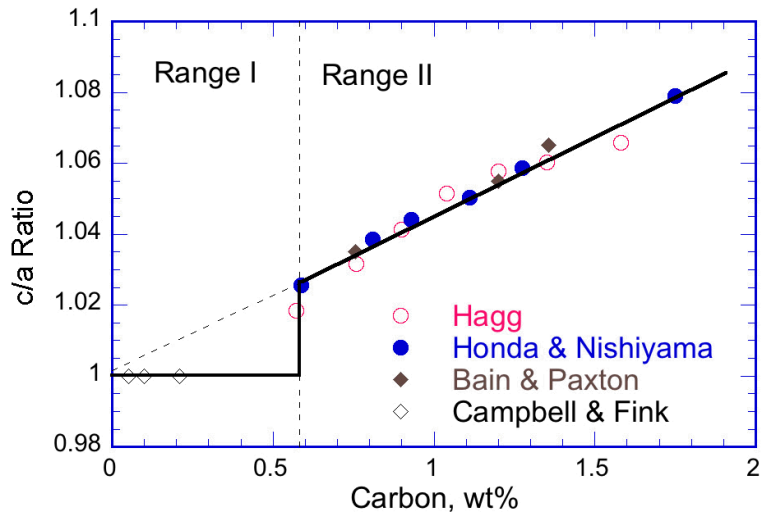

Fig. 4. c/a ratio vs. carbon content of quenched martensite in Fe-C steels

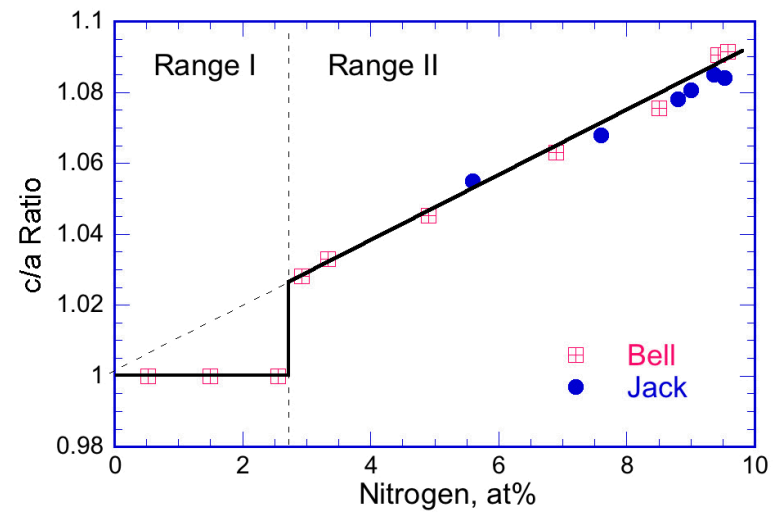

Fig. 5. c/a ratio vs. nitrogen content of quenched martensite in Fe-N steels

The above observations are interpreted as follows: Range II involves the traditional transformation from the FCC structure to the BCT structure. On the other hand, it is proposed that Range I involves a double transformation process. That is, the FCC structure first transforms to the HCP structure followed by a second transformation to the BCC structure. An explanation for these conclusions is proposed based on the role of valence in describing crystal structure of the elements utilizing the Engel-Brewer theory.

\section{The Engel-Brewer Theory of Crystal Strucures}

Engel and Brewer in the 1950's developed a theory that related the valence of pure metals (based on the outer $\mathrm{s}$ and $\mathrm{p}$ electrons) to their crystal structures [6]. The theory was amplified and discussed by Hume-Rothery [7]. The Engel-Brewer theory postulates that elements with the BCC structure have one electron in the outermost $(s, p)$ shells. Elements with the HCP structure have two electrons in the outermost shell and elements with the FCC structure will have three electrons in the outermost shell. This view is supported by the location of the elements in the periodic table. For example, elements with the HCP structure are adjacent to a BCC element on one side and to an FCC element on the other side [8]. This indicates that the HCP structure is closely tied to the BCC and FCC structure. The c/a ratio of HCP elements is never the ideal one expected from perfect 
packing of the atoms. This suggests that the electronic structure of $\mathrm{HCP}$ elements may be a mixture of valence one and valence three electrons from the adjoining $\mathrm{BCC}$ and $\mathrm{FCC}$ elements.

Additional support for this view is available from studies of solid state diffusion and mechanical behavior of the elements. Diffusion studies reveal that BCC elements show the fastest diffusion rates, followed by the HCP elements, and FCC elements show the slowest rates when compared at the same homologous temperature [9]. The mechanical properties of HCP metals show characteristics that are between those observed for BCC and FCC metals. HCP metals show strain hardening behavior like those observed in FCC metals, but temperature dependence of the flow stress like those observed in BCC metals [10]. In addition, the projected atom size of adjoining elements in the periodic table shows the atom size to increase in the order BCC, $\mathrm{HCP}$ and FCC. Iron should show the same increase in atom size with crystal structure change. The result is expected because as an s electron is added to BCC iron to form the HCP structure the atom can be expected to increase. Further increase in size of the iron atom will occur as a plectron joins to form the FCC structure.

\section{A Solution to the Problem}

Electronic contributions to the transformation process in polymorphic metals are generally not considered. These contributions should be equally applicable to alloy systems including Fe-C and $\mathrm{Fe}-\mathrm{N}$ steels. In these cases, the formation of martensite is the result of transformation. The basis for martensite formation is related to mechanical shearing processes involving close-packed planes and close-packed directions in each of the respective crystal structures [4,11]. No consideration of the valence electron changes is taken into account. The actual process during transformation is likely guided by electro-mechanical factors and not solely mechanical. Returning now to the results shown in Fig. 4, it was proposed that transformation in Range I is a two step process. The FCC austenite transforms to the HCP structure followed by a second transformation to the BCC structure. The formation of the HCP structure is made possible because of the internal pressure that is created during quenching that raises the pressure above the triple point. The transformation from FCC to HCP is relatively easy since the close-packed planes (where slip will occur) are in the same direction during transformation, only the stacking sequence is changed from $a b c a b c$ to $a b a b a b$. Figure 6 shows one possible way for this transformation to occur. An electromechancal process for transformation of FCC austenite to HCP structure is depicted. Shear stress between C and A planes in the initial state is activated to form A and B planes. Simultaneously, an opposite shear stress between atoms in the $\mathrm{B}$ and $\mathrm{C}$ planes is activated to change the position of the atoms forming $\mathrm{A}$ and $\mathrm{B}$ planes. The result is formation of the HCP structure with a valence of two. The proposed transformation is a form of twinning and similar to a model described by Bilby and Christian [12].

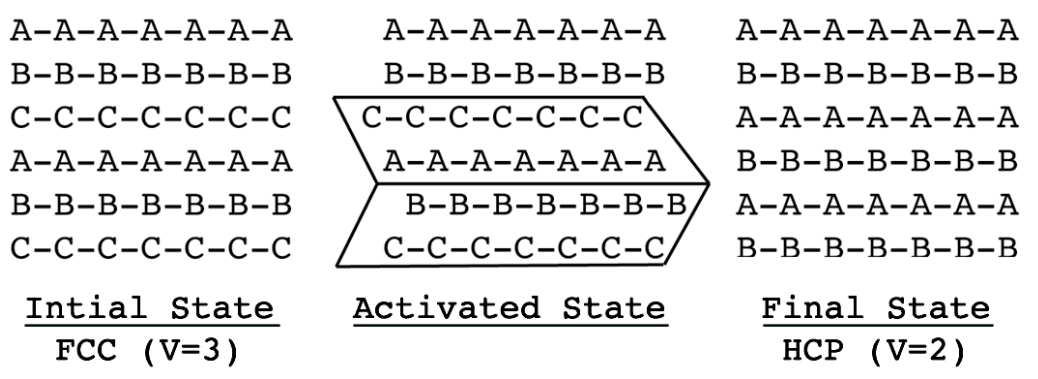

Fig. 6. Transformation process for FCC to HCP 
The second step involves the transformation of the HCP structure to the BCC structure. The electro-mechanical concept should be equally applicable. In this case, shear occurring on the basal plane and in the close packed direction in the HCP structure will lead to the BCC structure that is related to the (101) slip plane and the [111] slip direction.

In a comparison of the c/a ratio of quenched $\mathrm{Fe}-\mathrm{C}$ and $\mathrm{Fe}-\mathrm{N}$ alloys (Figs. 3 and 4) it was indicated that the same fixed amount of interstitial atom addition, namely 2.85 atom percent was present at the break point between Ranges I and II. This remarkable coincidence suggests that the transformation mechanism changes when a fixed number of excess electrons from carbon or nitrogen additions are reached. The valence state of carbon and nitrogen in iron may be the same inasmuch each interstitial element is known to form the same compound, $\mathrm{Fe}_{2} \mathrm{C}$ and $\mathrm{Fe}_{2} \mathrm{~N}$. This observation, together with the valence effect on the crystal structure of iron, requires a revision of the phase diagram for the FCC-HCP-BCC transformation. Beyond $0.6 \mathrm{wt} \% \mathrm{C}(2.85$ at $\%)$ the HCP structure will not form. An explanation is that $0.6 \mathrm{wt} \% \mathrm{C}$ is the limit of solubility of carbon in the HCP structure of iron under the temperature and pressure conditions during quenching. The FCC structure becomes more stable than the HCP structure. This is also consistent with the fact that carbon expands the FCC gamma loop. One can expect that alloying elements that expand the gamma loop, such as nickel, will inhibit formation of the HCP structure. Indeed, the work of Winchell and Cohen on Fe-C alloys containing a large amount of nickel have shown that the formation of the BCT structure is observed even at carbon contents as low as $0.05 \mathrm{wt} \%[11,13]$. In an opposite sense, addition of ferrite stabilizing alloying elements may expand Range I to carbon contents above $0.6 \mathrm{wt} \% \mathrm{C}$.

The elusive HCP structure of iron has been observed at room temperature and atmospheric pressure. Epsilon (HCP) martensite has been reported in the 300 series of stainless steels [14]. These steels contain a large amount of chromium (a ferrite stabilizer) and nickel (an austenite stabilizer) with $0.08 \% \mathrm{C}$. Chromium has a valence of one and nickel has a valence of three. The creation of epsilon martensite is a result of transformation from the FCC structure to the HCP structure driven by cold-working. It is a non-magnetic, hexagonal close-packed structure. As the amount of cold-work is increased the $\varepsilon$-martensite structure transforms to $\alpha$-martensite that is ferromagnetic with a body-centered cubic structure. This indicates that the BCC structure of martensite is more stable than the HCP structure of martensite. Here then, one sees the sequential transformation from FCC to HCP to BCC that supports the Engel-Brewer valence theory.

The mechanisms of martensite formation have been described in great detail. The resulting microstructures have been studied by Marder and Krauss [15]. In general, it appears that a lath-like structure is observed at low carbon contents and a plate-like structure is observed at high carbon contents. No sharp changes in structure, however, are evident that can be related to the sharp discontinuity in the c/a ratio at $0.6 \mathrm{wt} \%$ carbon. The consideration of energy changes in transforming austenite to martensite, and of the energy required for shear displacement have been discussed by Zener [16] and by Cottrell [17]. It was concluded by Zener that "the transition of martensite from a tetragonal lattice to a cubic lattice is interpreted as a change from an ordered distribution of carbon to a random distribution". A sharp discontinuity in structure is not predicted. Zener's theory will be discussed later when the strength characteristics of quenched Fe-C steels are described.

So far, our attention was on the formation of martensite in Range I (Fig. 4). The transformation in Range II involves a progressive change in the c/a ratio with increase in carbon content. This was 
interpreted by Bain [18 and discussion in reference 1] as a natural transformation of the FCC structure to a BCT structure with a c/a ratio of 1.4 that would have collapsed to the BCC structure. This is true for the case of pure iron. The situation is different in the case of Fe-C steels. Solute carbon atoms segregate during transformation to preferential sites in the BCT structure to prevent total collapse of the BCT structure. The model predicts the linear increase in the c/a ratio with carbon content as a consequence of the increase amount of solute carbon available for solute segregation. The Bain model cannot explain the sudden change in the c/a ratio carbon when it becomes unity at carbon contents below $0.6 \mathrm{wt} \% \mathrm{C}$.

\section{Strength of Quenched Fe-C Steels}

The strength of quenched Fe-C steels has been studied by many investigators. These studies are pertinent to an understanding of the structure of the quenched steels. Figure 7 shows the influence of carbon on the hardness of quenched iron-carbon steels [1]. Since hardness is a measure of the strength, the terms strength and hardness will be used interchangeably. A vertical line is drawn at 0.6 wt \%C representing the separation of Range I and Range II. Although only a single transformation occurs in Range II, there are two separate lines drawn. The lower line shows the hardness change with carbon content in the as-quenched condition where the structure is BCT. As can be seen the strength increase is much slower than that observed in Range I where the BCC structure was obtained. The major reason for this small change in hardness is that the carbon atoms that lead to tetragonality are in solution and do not contribute significantly to the strength. The upper line shows the increase in strength by low temperature tempering by carbon diffusion from the tetragonal sites in the BCT structure to form precipitates. This is because the dissolved carbon agglomerates to form nano-size particles and is responsible for the increase in strength. Further low temperature tempering shows that the first detected particles are paramagnetic epsilon carbides, $\mathrm{Fe}_{7} \mathrm{C}_{3}$ [19]. Additional low temperature tempering leads to rod-shaped carbides $\left(\mathrm{Fe}_{5} \mathrm{C}_{2}\right.$ or $\mathrm{Fe}_{3} \mathrm{C}$ ) that are ferromagnetic. The small amount of retained austenite in quenched $\mathrm{Fe}-\mathrm{C}$ steels does not transform until temperatures are reached that leads to a decrease in strength from tempering.

The maximum hardness of the quenched iron carbon steels as a function of carbon content, as shown in Fig. 7, cannot be attributed to solid solution hardening. This is because the crystal structure is body-centeredcubic with the c/a ratio equal to unity. If all carbon is in solution it would expand the lattice of BCC iron and this is not observed. Therefore one is to conclude that the carbon atoms must have coalesced to form a cluster of carbon atoms that is a precipitate with its own density differing from the iron-martensite matrix. That is, the tempering process by precipitation hardening was proceeding during the cooling step of quenching. This has been proposed by Robertson [20] and by Greninger and Troiano [21] and has been given the term of auto-tempering. That is, the particles were created during the cooling process of martensite formation and not isothermally.

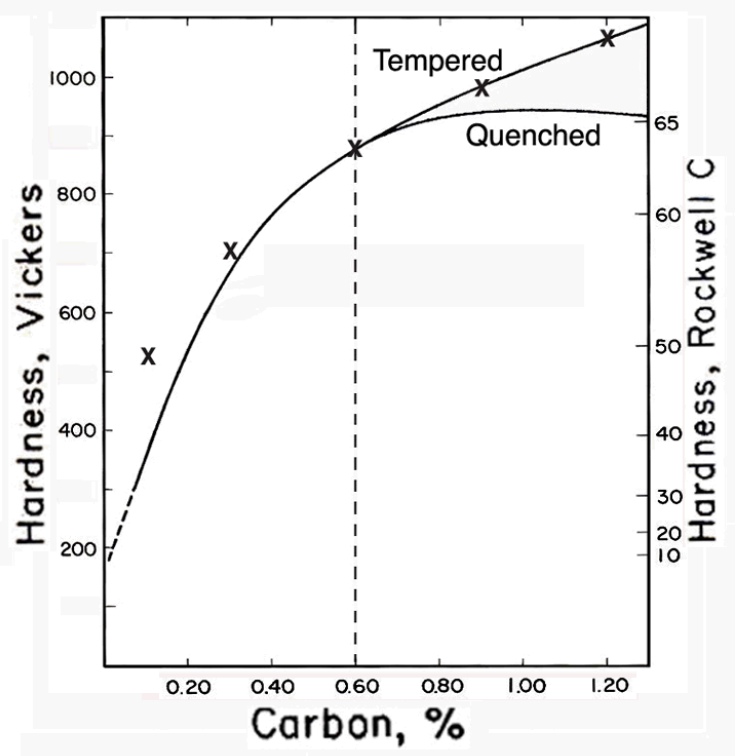

Fig. 7. Hardness vs. carbon content of quenched and tempered martensites in $\mathrm{Fe}-\mathrm{C}$ steels. Symbol X's represent the predicted strengths from particles. 
The size of these particles must be very small inasmuch as they have not been definitively observed. In fact, this remains a mystery and requires understanding how the transformation process can bring the carbon atoms together. Zhao et al [22] estimated, on thermodynamic grounds, that the minimum embryonic size is about $1 \mathrm{~nm}$. The present proposed transformation mechanism concludes that most of carbon atoms are not in solution in the BCC iron matrix. The Zener theory of solute redistribution is therefore not applicable to understanding the martensitic structure of quenched Fe-C steels.

It is also possible to estimate a minimum size from phenomenological relations developed for yield stress-particle size relations in Fe-C steels $[23,24]$. The relation is given as $\sigma_{\mathrm{y}}=\mathrm{B}\left(\mathrm{D}_{\mathrm{s}}{ }^{*}\right)^{-0.5}$ where $D_{s}{ }^{*}$ is the surface to surface interparticle spacing and $\mathrm{B}=395 \mathrm{MPa} \mu \mathrm{m}^{-0.5}$. The interparticle spacing is related to the volume fraction of particles, $f_{v}$, and the particle size, $d$, by $D_{s}{ }^{*}=1.22$ $\left\{\left(\pi / 4 \mathrm{f}_{\mathrm{v}}\right)^{0.5}-1\right\} \mathrm{d}$. By converting the hardness of a quenched $1.2 \mathrm{wt} \% \mathrm{C}$ material to the yield stress one obtains $\sigma_{\mathrm{y}}=4200 \mathrm{MPa}$. The yield strength was calculated from $\sigma_{\mathrm{y}}=\mathrm{H}_{\mathrm{v}} / \mathrm{C}$ where $\mathrm{C}=2.5$ in the range of $\mathrm{H}_{\mathrm{v}}$ values from 6.5 to 11.5 [23]. If one assumes that the cluster of carbon atoms is an embryonic diamond particle, the volume fraction of particles is 0.0267 for the $1.2 \mathrm{wt} \% \mathrm{C}$ steel. The result is that the calculated value of the particle size is $1.7 \mathrm{~nm}$. This is close to the theoretically predicted value. Subsequent tempering would lead to the creation of well-documented carbides, in the order of increasing iron content, namely, $\mathrm{Fe}_{2} \mathrm{C}, \mathrm{Fe}_{2.33} \mathrm{C}, \mathrm{Fe}_{2.5} \mathrm{C}$ and $\mathrm{Fe}_{3} \mathrm{C}$. The predicted strength of the nano-size diamond particles as a function of the carbon content, using $\mathrm{d}=$ $1.7 \mathrm{~nm}$ over the range of carbon contents from 0.1 to $1.2 \mathrm{wt} \% \mathrm{C}$ with $\mathrm{X}$ symbols. Predicted values are in close agreement with experimental data. Below $0.3 \mathrm{wt} \% \mathrm{C}$ the predicted strength is higher than the experimental strength. Selection of a constant particle size $(\mathrm{d}=1.7 \mathrm{~nm})$ at various carbon contents in the quenched Fe-C steels has support of the work of Kurdjumov [25]. The author showed that the observed particle sizes were about the same independent of carbon content

Observation of the proposed nano-size particles in quenched Fe-C steels has been elusive. Indirect evidence, however, exists from density and electrical conductivity experiments [20]. For example, the decrease in density of the quenched steels as a function of increasing carbon content is quantitatively explained by the presence of the low-density (3.5) diamond particles. Furthermore, the decrease in electrical conductivity of the quenched steel may be related to the presence of the four valence diamond particles that can be expected to scatter the conduction electrons in iron.

\section{Acknowledgments}

Part of the work described here was performed under the auspices of the U.S. Department of Energy by the University of California, Lawrence Livermore National Laboratory under Contract No. W-7405-Eng-48.

\section{References}

[1] E.C. Bain and H.W. Paxton: Alloying Elements in Steel (ASM, Metals Park, Ohio, 1966)

[2] W.L. Fink and E.D. Campbell: Trans. Am. Soc. Steel Treat, Vol. 9 (1926), pp. 717-752.

[3] K. Honda and Z. Nishiyama: Science Reports, Tohoku Imperial Univ. Vol. 21 (1932), p. 299; Trans. Am. Soc. Metals Vol. 20 (1932), p. 464.

[4] M. Cohen: Phase Transformations in Solids (John Wiley \& Sons, New York 1951), p. 588 
[5] W.S. Owen, E.A. Wilson and T. Bell: High Strength Materials (V.F. Zackay Ed., John Wiley \& Sons, New York 1965), pp. 167-212.

[6] L.Brewer: ibid, p. 12.

[7] W. Hume-Rothery: Prog. Mater. Sci. Vol. 13 (1968), p. 229.

[8] O.D. Sherby and J. Wadsworth: LLNL reports, May 25, 1999 and Nov. 4, 1999.

[9] J.R. Cahoon and O.D. Sherby: Metall. Mater. Trans. Vol. 23A (1992), p. 2491.

[10] O.D. Sherby and C.M. Young: Plastic Deformation of Materials (J.C.M. Li and A.K. Mukherjee, Eds. Am. Soc. Metals, Metals Park, Ohio 1975), Vol. 6, pp. 487-541.

[11] M. Cohen: Trans. Metall. Society of AIME Vol. 224 (1962). p. 638.

[12] B.A. Bilby and J.W. Christian: Jnl. Iron and Steel Inst. Vol. 197 (1961), p. 122.

[13] P.G. Winchell: The Structure and Mechanical Properties of Iron-Nickel-Carbon Martensites (Sc.D. Thesis, MIT 1958).

[14] V. Seetharamen and R. Krishman: J. Mater. Sci. Vol. 16 (1981), p. 523.

[15] A.R. Marder and G. Krauss: Trans. ASM Vol. 60 (1967), p. 651.

[16] C. Zener: Trans. AIME Vol. 167 (1946), p. 550.

[17] A.H. Cottrell: An Introduction to Metallurgy (Edward Arnold Publishers, Ltd, London 1967).

[18] E.C. Bain: Trans. AIME Vol. 70 (1924), p. 25.

[19] G.R. Speich: Trans. Met. Soc. AIME Vol. 245 (1969), p. 2553.

[20] H. Carpenter and J.M. Robertson: Metals (Oxford University Press, 1939).

[21] A.B. Greninger and A.R. Troiano: Trans. ASM Vol. 28 (1940), p. 537.

[22] M.C. Zhao, Y. Hanamura, H. Qui, and K. Yang: Mater. Trans. JIM Vol. 46 (2005), p. 784.

[23] C.K. Syn, D.R. Lesuer and O.D. Sherby: Mater. Sci. Tech. Vol. 21 (2005), p. 317.

[24] D.R. Lesuer, C.K. Syn and O.D. Sherby: submitted to Mater. Trans. JIM (2006).

[25] G.V. Kurdjumov: J. Iron and Steel Inst. Vol. 195 (1960), p. 26. 